\title{
Research on Contour Plane Coverage of 20-unit Localizer Antenna Array
}

\author{
C.Q.Qu ${ }^{+}$, Y.He, L.Zuo
}

East China Regional Air Traffic Management Bureau of Civil Aviation of China, China, Shanghai 200335

\begin{abstract}
Localizer beacon provides horizontal indication to airplane. The signal radiated from localizer antennas makes aircraft aim at the center line of runway. Also, the localizer beacon provides its particular identified signal of Instrument Landing System (ILS). Whether the signal coverage zone radiated from the localizer antenna system is satisfied the coverage requirement plays a decisive role in flight check. The Earth curvature effect was considered, consequently, the corresponding error of height and distance were also revised in wide area situation. The three-dimensional mathematical model of localizer beacon of 7220A was established in detail. Both the horizontal $\left(\theta_{\mathrm{h}}: 0^{\circ} \sim 360^{\circ}\right)$ and vertical $\left(\theta_{\mathrm{v}}: 0^{\circ} \sim 180^{\circ}\right)$ electromagnetic field distribution of Logical Periodic Dipole Antenna (LPDA) array were presented. According to flight check procedure, the electromagnetic field distributed was further researched in specific contour plane. The height of the localizer antenna $\left(h_{a}\right)$ has a close relationship to signal distribution. So it plays an important part in the intensity of radio frequency $(\mathrm{RF})$. The contour plane higher $\left(\mathrm{h}_{\mathrm{fly}}=1200 \mathrm{~m}\right)$ and lower $\left(\mathrm{h}_{\mathrm{fly}}=300 \mathrm{~m}\right)$ than that of the routine flight altitude $\left(\mathrm{h}_{\mathrm{ffl}}=600 \mathrm{~m}\right)$ with a series of height of antenna $\left(\mathrm{h}_{\mathrm{a}}=2.5 \mathrm{~m}, 3.0 \mathrm{~m}, 3.5 \mathrm{~m}, 4.0 \mathrm{~m}\right)$ were also analyzed.
\end{abstract}

Keywords: Localizer Beacon, Contour Plane, Signal Coverage, Antenna Height

\section{Introduction}

The Instrument Landing System (ILS), had its beginnings in the United States and England during the years 1939 to 1945[1]. Since then, ILS became the international standard system for approach and landing guidance. ILS was adopted by International Civil Aviation Organization (ICAO) in 1947 and will be in service until at least 2020. The ILS normally consists of a VHF "Localizer (LOC)" for runway alignment guidance, a UHF "Glide Path (GP)" for elevation guidance and "Marker Beacons (MB)" for providing key checkpoints along the approach. The MB are replaced or supplemented, at some time, by a "Distance Measuring Equipment (DME)" to provide continuous reading of distance.

The types of localizer beacon were the most abundant in ILS equipments. According to actual needs, they came out one after another. Such as series the early 3500-series: 3522[2], 3523B [3], 3524[4], 3525 [5], 3526[6] and the later 7000-series: 7212A[7], 7212C[8], 7216A[9], 7216C[10], 7220A[11], 7220B[12] were produced by Normarc factory; and single frequency: 8-unit moderate-aperture, 12-unit medium-aperture, dual frequency: 13-unit wide-aperture, 21-unit ultra wide-aperture[13], and 420-series: 14-unit, 20-unit manufactured by Thales company; dual frequency:14-unit, 16-unit, 20-unit were designed one after another by Selex company.

In the paper, the mathematical model of LDPA array of localizer beacon was explicitly established to analyze the 7220A antenna array of ILS. The distribution of radiated electromagnetic signal was simulated by software Matrix Laboratory (Matlab). The theoretical analyze combined with the specific standard of ICAO was presented.

\footnotetext{
+ Corresponding author. Tel.: + 86-13917093997;

E-mail address: qcq04@163.com
} 


\section{Result and Discussion}

\subsection{Introduction of 7220 A Antenna System}

\subsubsection{Antenna Distribution Unit (ADU)}

The ADU feeds the antenna elements with the proper amplitude and phase of the Carrier and Sideband (CSB) and Sideband Only (SBO) signals. The CSB signal plays a major part in the coverage, consists of Course (COU) and Clearance (CLR). The former one provides a sharp lob near the course line (CL) (about $\pm 5^{\circ}$ ) and the later one is used to satisfy the wide angle (more than $\pm 35^{\circ}$ ) coverage requirement. By changing the amplitude of the SBO feeding the ADU, the Course Sector Width is adjusted. Table 1 shows design data for the antenna system. The SBO relative value is design for the Displacement Sensitivity (DS) is $4.0^{\circ}$. The Amplitude values are given in relative volts, phase in electrical degrees.

From the table, the test data can be measured by network analyser through four input ports and twenty output ports of $\mathrm{ADU}$, the distance from the centre line of every antenna has been checked by flexible rule, the error between the theoretical and measured values is less than $0.02 \mathrm{~m}$, and the theoretical distribution also can be found in the technical manual [11], and the information of CSB and distance of each antenna would be used in below discussion.

Table.1: Normarc 7220A antenna system signal distribution and antenna elements $\left(\mathrm{DS}=4.0^{\circ}\right)$

Note: The voltage amplitudes are relative to the CSB Course amplitude at antenna 9.

\begin{tabular}{|c|c|c|c|c|c|c|c|c|c|}
\hline $\begin{array}{c}\text { Antenna } \\
\text { No. }\end{array}$ & $\begin{array}{c}\text { Dist } \\
\text { From CL } \\
(\mathrm{m})\end{array}$ & $\begin{array}{c}\text { COU } \\
\text { CSB } \\
\text { Ampl.(V) }\end{array}$ & $\begin{array}{c}\mathrm{COU} \\
\mathrm{CSB} \\
\left.\operatorname{Phase}^{\circ}\right)\end{array}$ & $\begin{array}{c}\text { COU } \\
\text { SBO } \\
\text { Ampl.(V) }\end{array}$ & $\begin{array}{c}\mathrm{COU} \\
\mathrm{SBO} \\
\left.\operatorname{Phase}^{\circ}\right) \\
\end{array}$ & $\begin{array}{c}\text { CLR } \\
\text { CSB } \\
\text { Ampl.(V) }\end{array}$ & $\begin{array}{c}\text { CLR } \\
\text { CSB } \\
\text { Phase }\left(^{\circ}\right)\end{array}$ & $\begin{array}{c}\text { CLR } \\
\text { SBO } \\
\text { Ampl.(V) }\end{array}$ & $\begin{array}{c}\text { CLR } \\
\text { SBO } \\
\text { Phase }\left(^{\circ}\right)\end{array}$ \\
\hline 1 & -26.03 & 11 & 0 & 3.29 & -90 & & & & \\
\hline 2 & -22.54 & 15 & 0 & 4.20 & -90 & & & 0.32 & 90 \\
\hline 3 & -19.23 & 29 & 0 & 5.75 & -90 & 5.65 & 180 & 0.32 & 90 \\
\hline 4 & -16.09 & 45 & 0 & 6.59 & -90 & 5.65 & 180 & & \\
\hline 5 & -13.13 & 66 & 0 & 6.66 & -90 & 11.72 & 180 & 0.54 & -90 \\
\hline 6 & -10.34 & 82 & 0 & 6.00 & -90 & 11.72 & 180 & 0.32 & -90 \\
\hline 7 & -7.73 & 93 & 0 & 4.82 & -90 & 32.17 & 180 & 4.32 & -90 \\
\hline 8 & -5.30 & 100 & 0 & 3.38 & -90 & 12.86 & 0 & 4.32 & -90 \\
\hline 9 & -3.04 & 100 & 0 & 1.89 & -90 & 94.60 & 180 & 9.25 & -90 \\
\hline 10 & -0.95 & 93 & 0 & 0.55 & -90 & 204.83 & 0 & 37.52 & -90 \\
\hline 11 & 0.95 & 93 & 0 & 0.55 & 90 & 204.83 & 0 & 37.52 & 90 \\
\hline 12 & 3.04 & 100 & 0 & 1.89 & 90 & 94.60 & 180 & 9.25 & 90 \\
\hline 13 & 5.30 & 100 & 0 & 3.38 & 90 & 12.86 & 0 & 4.32 & 90 \\
\hline 14 & 7.73 & 93 & 0 & 4.82 & 90 & 32.17 & 180 & 4.32 & 90 \\
\hline 15 & 10.34 & 82 & 0 & 6.00 & 90 & 11.72 & 180 & 0.32 & 90 \\
\hline 16 & 13.13 & 66 & 0 & 6.66 & 90 & 11.72 & 180 & 0.54 & 90 \\
\hline 17 & 16.09 & 45 & 0 & 6.59 & 90 & 5.65 & 180 & & \\
\hline 18 & 19.23 & 29 & 0 & 5.75 & 90 & 5.65 & 180 & 0.32 & -90 \\
\hline 19 & 22.54 & 15 & 0 & 4.20 & 90 & & & 0.32 & -90 \\
\hline 20 & 26.03 & 11 & 0 & 3.29 & 90 & & & & \\
\hline
\end{tabular}

\subsubsection{Signal Synthesis}

The frequency (f) of CSB signal is taken $110.1 \mathrm{MHz}$, then the corresponding wavelength $(\lambda)$ is $2.72 \mathrm{~m}$. The transmitter power of CSB is $20 \mathrm{~W}$.

\subsubsection{Horizontal Signal Synthesis}

The $7220 \mathrm{~A}$ antenna array consists of twenty elements, the mirror symmetry from center generates ten pairs. The width of the antenna array is $52 \mathrm{~m}$, while the coverage zone of the radiated signal is far more than $5 \mathrm{~km}$. So the horizontal synthesized formula of CSB fits to far field model ${ }^{[14]}$, and the expression can be described as formula 1: 


$$
\operatorname{CSB}\left(\theta_{\mathrm{h}}\right)=\operatorname{LPDA}\left(\theta_{\mathrm{h}}\right) \cdot \sum_{n=1}^{10} 2 E_{n} \cos \left(\frac{2 \pi D_{n}}{\lambda} \sin \theta_{\mathrm{h}}\right) / \underline{\varphi_{\mathrm{n}}}
$$

The horizontal CSB signal comprises COU and CLR. The final synthesis is adopt by capture effect, the $360^{\circ}$ Omni-directional distribution can be seen in figure 1 . There is a sharp lobe right ahead (about $\pm 4^{\circ}$ ), devoted by COU, owns good anti-interference ability. The sector mainly supported by CLR is used to satisfy the wide-angle (more than $\pm 35^{\circ}$ ) signal coverage.

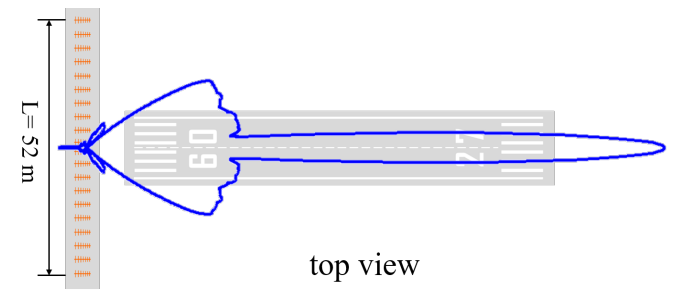

Fig.1: horizontal radiation pattern of $7220 \mathrm{~A}$

\subsubsection{Vertical Signal Synthesis}

Because the electromagnetic wave radiated by localizer beacon is horizontal polarization, the reflected signal would generate half wave loss $\left(180^{\circ}\right.$ phase delay). The vertical synthesis signal comprised direct signal and it's reflected one. So the flat ground in front of the localizer beacon plays an important part in the quality of final synthesis signal. The vertical synthesis signal of CBS can be described as formula 2:

$$
\operatorname{CSB}\left(\theta_{\mathrm{v}}\right)=\operatorname{LPDA}\left(\theta_{\mathrm{v}}\right) \cdot 2 \sin \left(\frac{2 \pi h_{\mathrm{a}}}{\lambda} \sin \theta_{\mathrm{v}}\right)
$$

It should be noted that the vertical signal distribution is related no only to the elevation angle but also to the height of the antenna $\left(h_{a}\right)$. Supposing the land is smooth. The lobes of synthesis signal in vertical plane (from $0^{\circ}$ to $180^{\circ}$ with flatten ground) with four different height are given in figure 2 . The phenomenon of uneven interval distribution (several lobes) is contributed to the mirror synthesis. While the poor amplitude of back lobe is originated from the function of LPDA. The front-to-back ratio of LPDA is designed for $26 \mathrm{~dB}$.

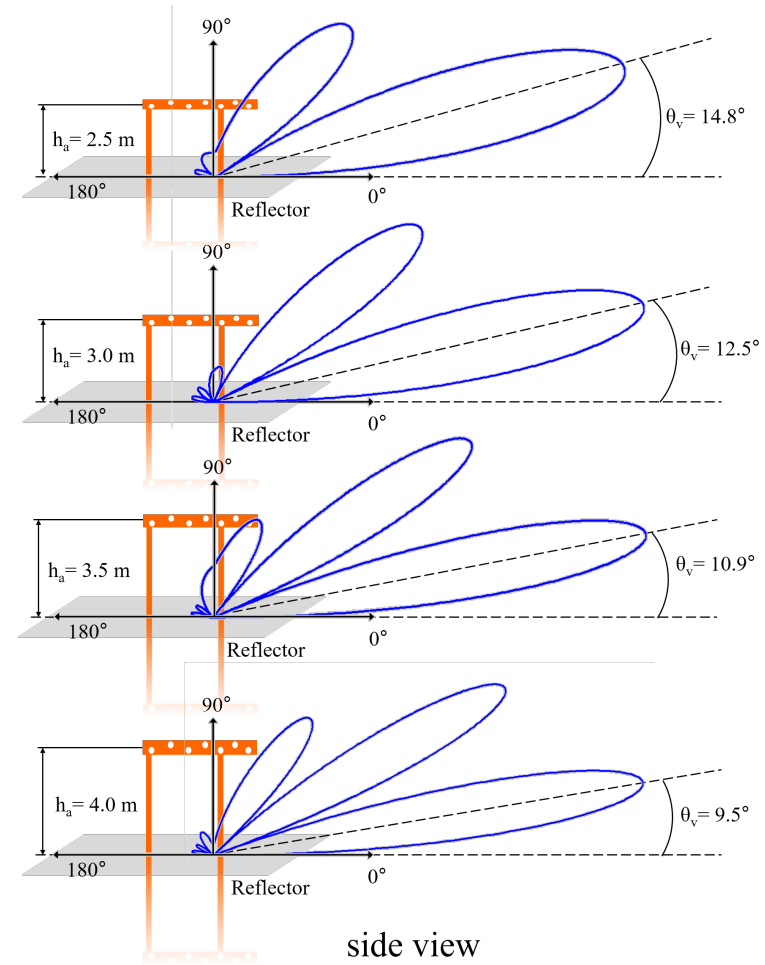

Fig.2: vertical radiation pattern of 7220A with different height of antenna. This vertical signal synthesis is based on the hypothesis that the reflector is smooth and flatten. The radiation signal of localizer antennas is horizontal polarization, the synthesis signal consists of direct signal and reflected signal. The reflected one from the reflector generates $180^{\circ}$ phase delay. 
The coverage zone of localizer beacon depends on the first lobe in front. Because of the LPDA function, the first lobe owns the maximum amplitude of all lobes distributed from $0^{\circ}$ to $180^{\circ}$ in vertical plane. The elevation angle $\left(\theta_{\mathrm{v}}\right)$ of first lobe has a strong relationship to $\mathrm{h}_{\mathrm{a}}$. The $\theta_{\mathrm{v}}$ would be depressed with increasing of $h_{a}$. There are four height of antenna $\left(h_{a}=2.5 \mathrm{~m}, h_{a}=3.0 \mathrm{~m}, h_{a}=3.5 \mathrm{~m}, h_{a}=4.0 \mathrm{~m}\right)$ would be researched below. In detail, there are two lobes for $h_{a}=2.5 \mathrm{~m}$ and three lobes for the other three one in first quadrant. Consequently, there are one zero zone for $h_{a}=2.5 \mathrm{~m}$ and double zero zone for the latter three height. Discussion below would analyze the interval coverage characteristics of the circle effect.

\subsection{Error Correction by Earth Curvature}

When the aircraft flies in sky with a certain altitude, the orbit in space is a contour plane. The contour plane is just like the surface of a sphere instead of a flat surface in fact. So the precise position on the contour plane should be revised for Cartesian coordinates of antenna system. The calculation discussed below is based on the hypothesis that the Earth is a spheroidal ball with flatten surface.

\subsubsection{Relationship between Coverage Altitude and Antenna Position}

It can be seen in figure 3 that the altitude of orbit of aircraft is changeable relative to the localizer. When the aircraft flies over the antenna, the height of aircraft relative to antenna $\left(\mathrm{H}_{\mathrm{a}}\right)$ is equal to the fly altitude $\left(\mathrm{h}_{\mathrm{fly}}\right)$. Besides, $\mathrm{H}_{\mathrm{a}}$ is lower than $\mathrm{h}_{\text {fly }}$.

The position that aircraft relative to the antenna should be achieved firstly, then the radio frequency (RF) level could be calculated in Cartesian coordinates accurately.

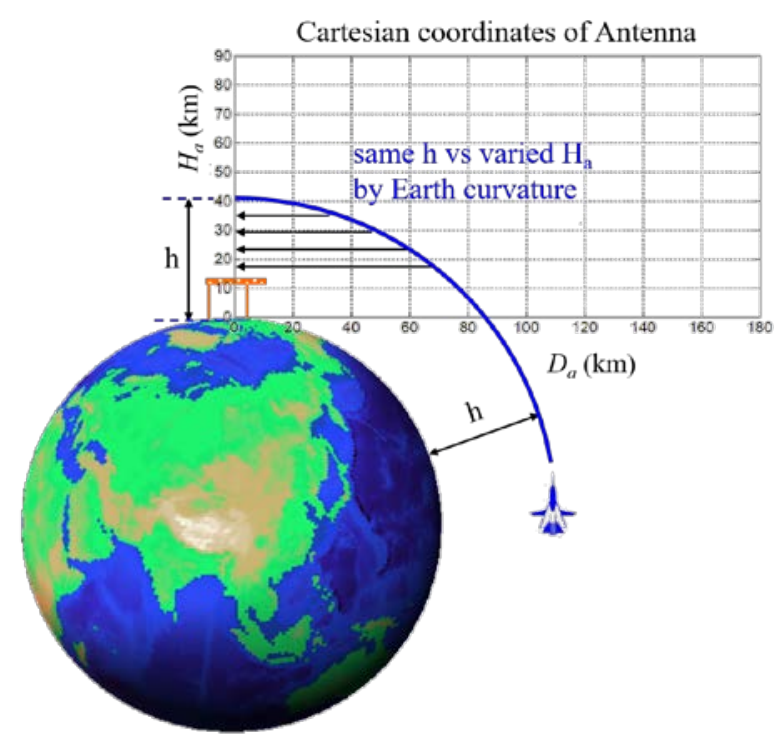

Fig.3: the height error caused by Earth curvature

\subsubsection{Coordinates Transformation}

In figure 4 , the transmitter point $\left(\mathrm{P}_{\mathrm{T}}\right)$ is the position of the antenna and the receive point $\left(\mathrm{P}_{\mathrm{R}}\right)$ is the position on fly orbit. On the aircraft, the distance to $\mathrm{P}_{\mathrm{T}}$ consists of horizontal coordinate distance, gap between two projections of longitude and latitude (d), and vertical difference of altitude, the height above sea level (h). In Cartesian coordinates, $\mathrm{P}_{\mathrm{T}}$ is original point, and the coordinate of the $\mathrm{P}_{\mathrm{R}}$ is $\mathrm{D}_{\mathrm{a}}$ for distance (x-axis) and $H_{a}$ for height (y-axis). The relationship between $(d, h)$ and $\left(D_{a}, H_{a}\right)$ is given below:

$$
\begin{aligned}
& D_{a}=(h+r) \cdot \sin (d / r) \\
& H_{a}=(h+r) \cdot \cos (d / r)-r
\end{aligned}
$$

The $r_{0}$ is the radius of Earth, namely $6370 \mathrm{~km}$. But considering the atmospheric refraction, $r$ is the equivalent radius of $r_{0}$. 


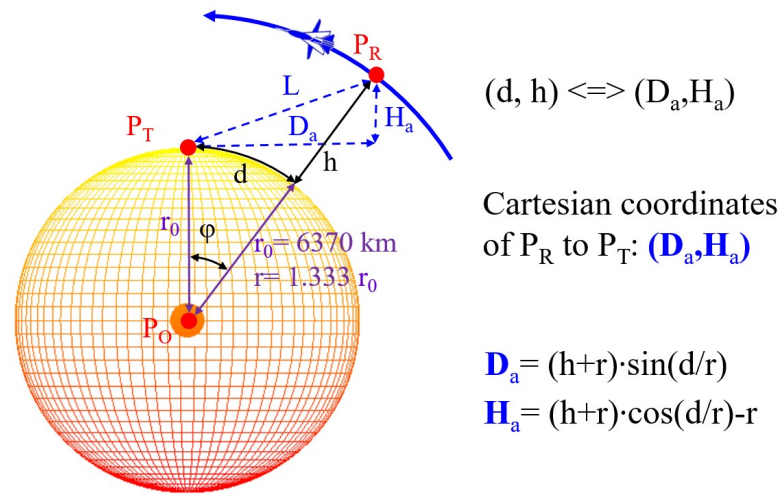

Fig.4: coordinates transformation relationship between $(\mathrm{d}, \mathrm{h})$ and $\left(\mathrm{D}_{\mathrm{a}}, \mathrm{H}_{\mathrm{a}}\right)$

\subsubsection{Error Analysis}

According to the transformation formula 3, the space coordinate of the fly orbit can be calculated in Cartesian coordinates. And the geometric error caused by Earth curvature can be compared.

There are two kind of error would be discussed: distance error and height error. With the variety of the distance between $P_{T}$ and $P_{R}$, distance error $\left(\Delta D_{a}\right)$ is the difference value between $D_{a}$ and $d$. while height error $\left(\Delta \mathrm{H}_{\mathrm{a}}\right)$ is the difference value between $\mathrm{h}_{\mathrm{fly}}$ and $\mathrm{H}_{\mathrm{a}}$.

\subsubsection{Distance Error}

To understand the difference of error specifically, there are three altitude of contour plane $\left(\mathrm{h}_{\mathrm{fly}}=30 \mathrm{~m}\right.$, $\mathrm{h}_{\text {fly }}=300 \mathrm{~m}, \mathrm{~h}_{\mathrm{fly}}=600 \mathrm{~m}$,) the calculation result can be found in figure 5 . The calculation was taken from formula 3. The distance was scanned until $300 \mathrm{~km}$, but for various $\mathrm{h}_{\mathrm{fly}}$, each $\Delta \mathrm{D}$ is negligible comparative to $\mathrm{D}_{\mathrm{a}}$. It can be seen in the insert that the lower $\Delta \mathrm{D}_{\mathrm{a}}$ of contour plane changes little within $30 \mathrm{~km}$, but shot up quickly outside $150 \mathrm{~km}$. The maximum value is just $60 \mathrm{~m}$ at $300 \mathrm{~km}$ for $\mathrm{h}_{\mathrm{fly}}=30 \mathrm{~m}$. So the $\Delta \mathrm{D}_{\mathrm{a}}$ doesn't play a decisive role in error revision.

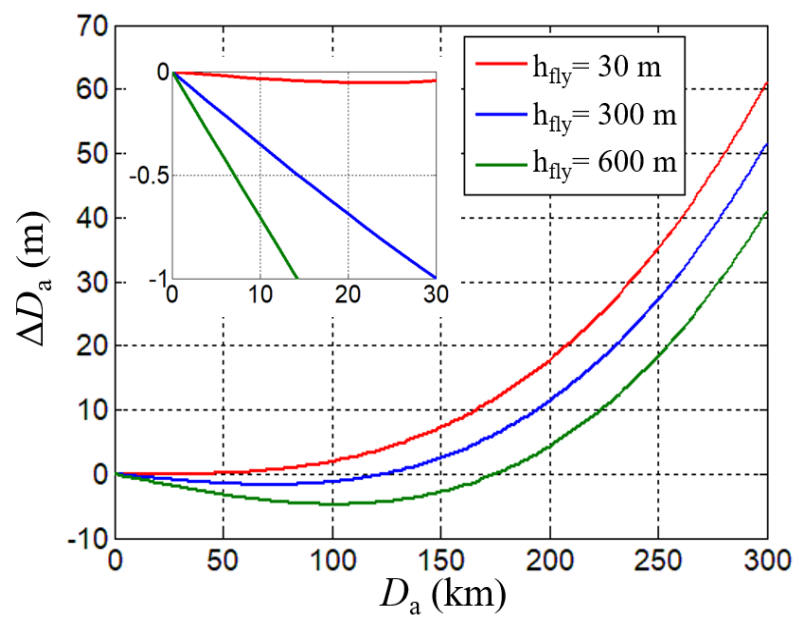

Fig.5: Distance errorcalculation with different fly height v.s. distance internal

\subsubsection{Height Error}

It can be seen in figure 6 that the difference of $\mathrm{h}_{\mathrm{fly}}$ has little influence on $\Delta \mathrm{H}_{\mathrm{a}}$, two curves are $\left(\mathrm{h}_{\mathrm{fly}}=30 \mathrm{~m}\right.$ and $\mathrm{h}_{\mathrm{fly}}=300 \mathrm{~m}$ ) almost coincident from the range up to $30 \mathrm{~km}$ far away. $\Delta \mathrm{H}_{\mathrm{a}}$ is monotonically increasing and has reached $53 \mathrm{~m}$ at $30 \mathrm{~km}$. The corresponding error of elevation angle $\left(\Delta \theta_{\mathrm{v}}\right)$ arrives at $0.1^{\circ}$. For glide angle $\left(\theta_{\mathrm{v}}=3^{\circ}\right)$, this error value seems dramatically serious, especially for glide path beacon, while relevant error of radio frequency $(\triangle \mathrm{RF})$ is $0.27 \mathrm{~dB}$. Evidently, height error carry a big weight on the effect of Earth curvature. 


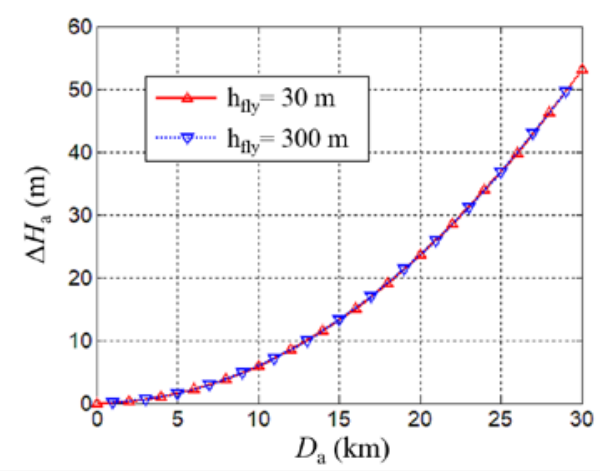

Fig.6: height error calculation with different fly height v.s. distance internal

To understand the characteristics of the vertical error systemically, three important parameters $\left(\Delta \mathrm{H}_{\mathrm{a}}, \Delta \theta_{\mathrm{v}}\right.$, $\Delta \mathrm{RF}$ ) are systematically simulated from the distance span $10 \mathrm{~km}$ to $300 \mathrm{~km}$, the calculation of parameters are listed in formula 4 and formula 5 . From table 2, at distance of $100 \mathrm{~km}$, the corresponding $\Delta \mathrm{RF}$ (comparative to flatten surface) arrives at $0.87 \mathrm{~dB}$. From the table 2, it can be find that $\Delta \theta_{\mathrm{v}}$ (the space geometric error caused by Earth Curvature) and $\Delta \mathrm{RF}$ are proportional to $\mathrm{D}_{\mathrm{a}}$ within $100 \mathrm{~km}$. Over this distance, the linear change rule still fits to $\Delta \theta$, but fades away for $\Delta \mathrm{RF}$. The change of $\Delta \mathrm{RF}$ was abated with the corresponding distance increasing.

$$
\begin{array}{r}
\Delta \theta_{\mathrm{v}}=\arctan \frac{\Delta H_{a}}{D_{a}} \\
\Delta R F=20 \lg \frac{\sin \frac{2 \pi h}{\lambda} \sin \left(3^{\circ}+\theta_{\mathrm{v}}\right)}{\sin \frac{2 \pi h}{\lambda} \sin \left(3^{\circ}\right)}
\end{array}
$$

Table.2: several error parameters with different distance

The data is from the case of $h_{a}=3 \mathrm{~m}$ and RF is chosen from the circumstance of $\theta_{\mathrm{v}}=3^{\circ}$

\begin{tabular}{cccc}
\hline $\mathrm{D}_{\mathrm{a}}(\mathrm{km})$ & $\Delta \mathrm{H}_{\mathrm{a}}(\mathrm{m})$ & $\Delta \theta_{\mathrm{v}}\left({ }^{\circ}\right)$ & $\Delta \mathrm{RF}(\mathrm{dB})$ \\
\hline 10 & 6 & 0.03 & 0.09 \\
20 & 24 & 0.07 & 0.18 \\
30 & 53 & 0.10 & 0.27 \\
50 & 147 & 0.17 & 0.45 \\
100 & 589 & 0.34 & 0.87 \\
200 & 2355 & 0.67 & 1.66 \\
300 & 5298 & 1.01 & 2.37 \\
\hline
\end{tabular}

\subsection{Analysis of Contour Plane Coverage}

The coverage performance in contour plane is directly related to the flight check procedure. The coverage requirement of localizer beacon and coverage characteristics of $7220 \mathrm{~A}$ system would be discussed below. The calculation is based on a hypothesis that the signal is spread through free space loss, the height of building and special terrain are not taken into account, and the blocking loss is neglected. The details of concrete simulated method of signal synthesis can be found in reference ${ }^{[14]}$. The coverage zone in identical altitude is a spherical surface called "contour plane coverage". Comparative to flatten ground, the calculation in wide area need consider the Earth curvature revision, which has been discussed above.

\subsubsection{Flight Check and Signal Coverage}

According to flight check procedure, the height of aircraft in approaching is $600 \mathrm{~m}$, taking the antenna array as the center with a radius of $100 \mathrm{~km}$. On this surface, the localizer filed signal was totally scanned, exhibited in figure 7 . The RF of the signal more than $-93 \mathrm{dBm}$ was marked by gradation color from cyan to violet. This is the effective coverage zone. The signal focus on the center owns the higher RF level, the maximum value reached $-17 \mathrm{dBm}$. But the center area was covered by the red sector and not seen clearly. 
The unshielded distribution for $\mathrm{h}_{\mathrm{fly}}=2.5 \mathrm{~m}$ can be found clearly in figure 8 . This red zone representatives the coverage requirement. This horizontal coverage ruled by Annex $10^{[15]}$, where a distance at least $46.3 \mathrm{~km}(25$ $\mathrm{Nm})$ within $\pm 10^{\circ}$ from the course line, and the limits reduced to $31.5 \mathrm{~km}(17 \mathrm{Nm})$ between $10 \sim 35^{\circ}$ from the front course line. The minimum field in this region must be more than $40 \mu \mathrm{V} / \mathrm{m}$.

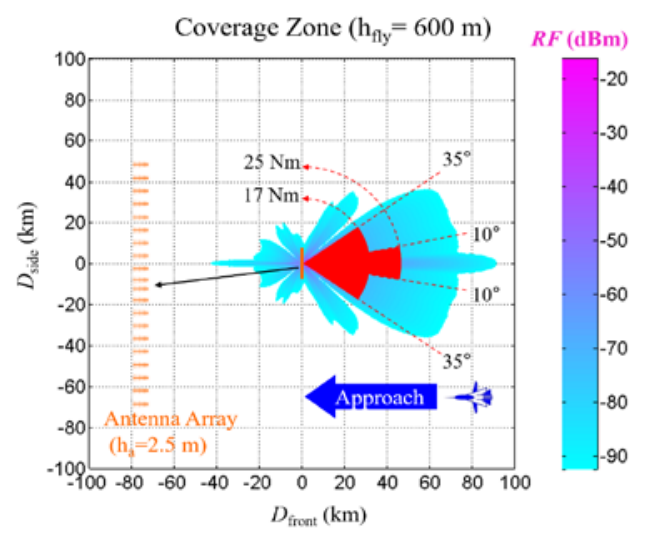

Fig.7 the simulated result (horizon distribution marked in cyan) of coverage zone of $7220 \mathrm{~A}$ with coverage requirement. In Chinese flight check rule, the minimum RF is $-93 \mathrm{dBm}$, the red sector zone marked in the center of the figure. The gradation from cyan $(-93 \mathrm{dBm})$ to violet $(-17 \mathrm{dBm})$ is the contour plane of CSB coverage in $600 \mathrm{~m}\left(\mathrm{~h}_{\mathrm{fly}}=600 \mathrm{~m}\right)$ for $\mathrm{h}_{\mathrm{a}}=$ $2.5 \mathrm{~m}$. This RF level responds to the lambda of localizer beacon is satisfied to the value ruled by Annex 10 .

In the contour plane, the distribution pattern is different from the horizontal radiation pattern showed in figure 1. Just like the LPDA, the front-to-back rate of horizon pattern is $26 \mathrm{~dB}$. However, for the contour plane, the maximum coverage distance $\left(\mathrm{d}_{\max }\right)$ is about $92 \mathrm{~km}$ in front of the antennas and approximately 42 $\mathrm{km}$ behind it. The front to back rate of the distance is just about $6.81 \mathrm{~dB}$, far less than $26 \mathrm{~dB}$. Right ahead the antenna array, marked in figure, the sharp lobe $\left( \pm 4^{\circ}\right)$ devoted by COU in figure 1 is serious shriveled in this contour plane, just has a poor coverage affect. While the CLR signal plays a significant role in coverage, meanwhile, the CLR owns a good steady fan-shaped distribution up to $\pm 40^{\circ}$. This design of $7220 \mathrm{~A}$ perfectly satisfies the coverage requirement (red zone). After that, the CLR signal is quickly reduced outside $\pm 40^{\circ}$, just a "tail" in $40 \sim 60^{\circ}$. In horizontal distribution, seen in figure 1 , the "small tail" is only inconspicuous but become strengthened in contour plane. This phenomenon doesn't come singly but in pairs, behind the antenna array, the lobes are also enlarged, especially the back one, almost longer than the main lobe.

Above all, the little lobes with large azimuth in horizontal distribution, the amplitude of the lobes would strengthen in contour plane. Consequently, the wide angle zone from $40^{\circ}$ to $180^{\circ}$ was still covered unnecessary in contour plane.

\subsubsection{Antenna Height Effect}

The height of transmitter antenna has an impact on vertical distribution, which was discussed above. The higher $h_{a}$ would bring the vertical radiated lobe down, the lower angle lobe is directly related to the coverage area of contour plane. The common height of antenna from $2.5 \mathrm{~m}$ to $4.0 \mathrm{~m}$ was taken into account. Applying the flight check altitude with $600 \mathrm{~m}$, the ideal situation (without obstacle shading) of coverage calculation results were showed in figure 8 . Compare to the coverage area of effective signal in figure 7 for $h_{a}=2.5 \mathrm{~m}$, the coverage zones of the other height $\left(\mathrm{h}_{\mathrm{a}}=3.0 \mathrm{~m}, 3.5 \mathrm{~m}, 4.0 \mathrm{~m}\right)$ were expanded several kilometer in front $\left(\mathrm{d}_{\max } \approx 92 \mathrm{~km}\right.$ for $\mathrm{h}_{\mathrm{a}}=2.5 \mathrm{~m}$ to $\mathrm{d}_{\max } \approx 95 \mathrm{~km}$ for $\mathrm{h}_{\mathrm{a}}=4.0 \mathrm{~m}$ ), and position for other azimuth also was enlarged simultaneously.

Referred in figure 2 above, the lower angle lobe with higher $h_{a}$, could satisfied the further distance coverage. The coverage area expanded gradually with the increase of corresponding $h_{a}$. When the ILS equipment has completed, if the localizer coverage was insufficient in first flight check. In special situation, raised $h_{a}$ to strengthen $R F$ lever is advisable. 


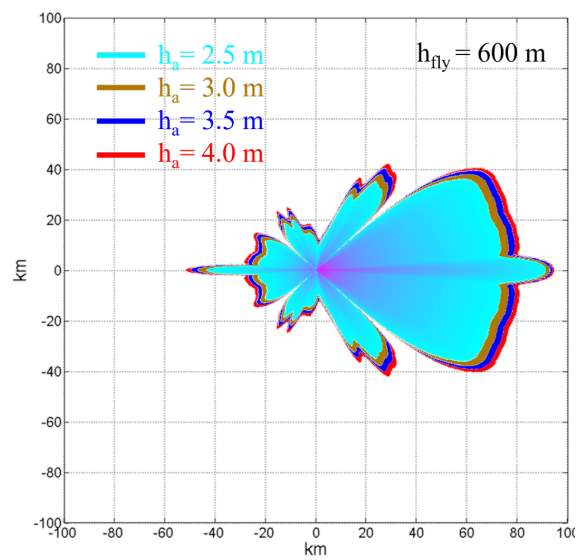

Fig.8: coverage zone in the altitude of $h_{\text {fly }}=600 \mathrm{~m}$ with different $h_{a}$. The maximum zone with $h_{a}=4.0 \mathrm{~m}$ (red area) placed at the bottom layer, the next one with $h_{a}=3.5 \mathrm{~m}$ (blue area) was placed on the bottom on, the minimum coverage zone with $h_{a}=2.5 \mathrm{~m}$ (cyan area) was placed on the top of the other three layers.

\subsubsection{Contour Plane Coverage Responding}

The vertical coverage corresponding exhibited that the signal is monotonically increasing below $9.5^{\circ}$ with a series of $h_{a}$, seen in figure 2. From a wide coverage zone perspective, the higher contour plane owns a larger area. To understand the circumstance of neighboring contour plane exactly, the altitudes above and below $h_{\text {fly }}=600 \mathrm{~m}$ were also researched in further simulation, the analyze result are listed in figure 9 and figure 10 respectively.

Lower contour plane $\left(h_{f l y}=300 \mathrm{~m}\right)$ : the identical simulation method with the circumstance for $h_{f l y}=600$ $\mathrm{m}$, just change the altitude information, not other extra condition mixed. The result in lower contour plane, half of the altitude with $h_{\text {fly }}=600 \mathrm{~m}$, there exists similar distribution patterns to that of $h_{\text {fly }}=600 \mathrm{~m}$. the coverage distribution also follows the rule that the higher $h_{a}$ owns the larger coverage zone. The difference is that the coverage area in this contour plane is shrunk. However, the shrunken zone with lower altitude remains satisfied the coverage requirement in this altitude.

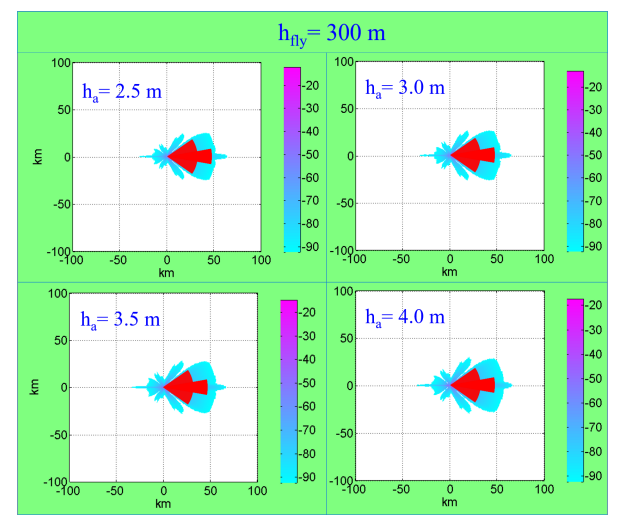

Fig.9: contour plane in $300 \mathrm{~m}$ high with various $\mathrm{h}_{\mathrm{a}}$. All of four simulated coverage zones can satisfied the coverage requirement. They also exhibited similar distribution feature.

Higher contour plane $\left(\mathrm{h}_{\mathrm{fly}}=1200 \mathrm{~m}\right)$ : In higher contour plane for double of the altitude with $\mathrm{h}_{\mathrm{fly}}=600 \mathrm{~m}$, the simulated result showed that the coverage area was enlarged, and beyond the scanned area with a radius of $100 \mathrm{~km}$ in front. Still, the higher $h_{a}$ owns the wider coverage sector. In actual, the maximum coverage distance $\left(d_{\max }\right)$ has arrived at $127 \mathrm{~km}$ for $h_{a}=2.5 \mathrm{~m}$ and $133 \mathrm{~km}$ for $h_{a}=4.0 \mathrm{~m}$. Far more than the required coverage zone with $46.2 \mathrm{~km}$ in front. The required zone (red one) is just a little bit in coverage area (cyan one). In this altitude, the airplane just entered into approaching procedure. And the Earth curvature effect plays an important role in such wide coverage area. This revised calculation result is more accurate for high altitude wide range coverage distribution. 


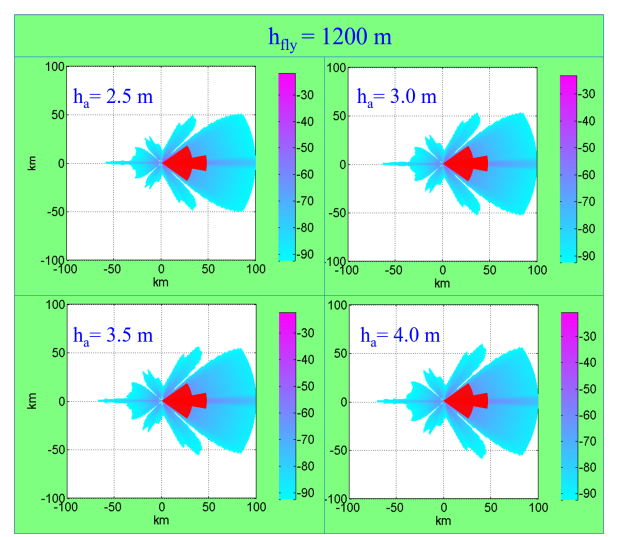

Fig.10: contour plane in $1200 \mathrm{~m}$ high with various $\mathrm{h}_{\mathrm{a}}$. The scan area was just a circle with a radius limited in $100 \mathrm{~km}$. In factor, all of four simulated coverage zones own more than $100 \mathrm{~km}$ with about $\pm 40^{\circ}$ sector. The color bar reflected the

RF level of every coverage distribution.

\subsubsection{Near Field Situation----Circle Effect}

Intensively, the signal in coverage zone does not totally meet coverage requirement. To perfectly understand the coverage characteristics, the near-field area with a simulated radius of $5 \mathrm{~km}$ has been investigated. There are some blind regions above the antenna array, seen in figure 11. Two kind of $h_{a}$ have been taken to analyze. For $h_{a}=2.5 \mathrm{~m}$, there is only one circle can be found. The circle is hard to find in 300 $\mathrm{m}$ high, and can been seen vaguely in $600 \mathrm{~m}$ high. However, it can been found clearly in $1200 \mathrm{~m}$ high. This blind circle originated from the vertical lobe interval, seen in figure 2. Between the first lobe and second one, there is a zero zone. The zero zone caused the coverage insufficient. And the other coverage insufficient region like hyperbolic curves is due to CLR distribution feature. For $h_{a}=4.0 \mathrm{~m}$, three lobes appear in first quadrant. So there are two zero zones among them, thereby, generate two circles in contour plane. However, the distance of circle zone is located in the runway. For approaching, this coverage insufficient area is not in use.

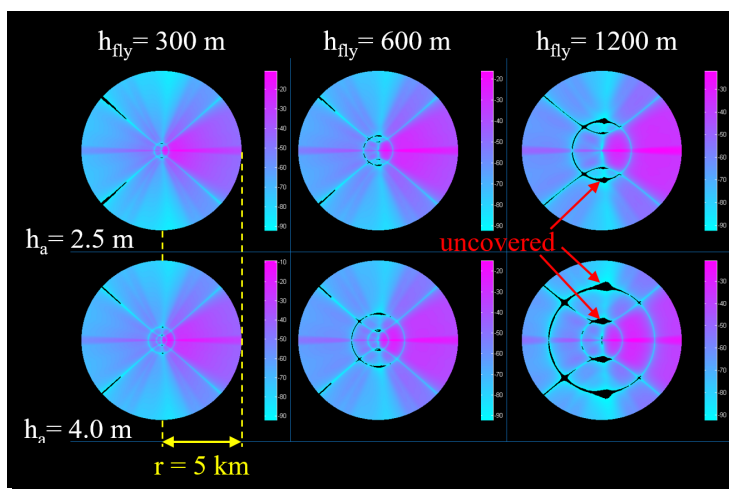

Fig. 11: high precision scanning: the case of $h_{a}=2.5$ and $h_{a}=4.0 \mathrm{~m}$ in three king of contour planes. The scanning range is a circle with a radius of $5 \mathrm{~km}$. There are some uncovered zone can be found at eight and ten o'clock, as well as single circle for $h_{a}=2.5 \mathrm{~m}$ and dual circles for $h_{a}=4.0 \mathrm{~m}$ with the altitude of $h_{\text {fly }}=1200 \mathrm{~m}$.

\section{Summary}

The signal coverage in contour plane of localizer beacon 7220A system has been investigated in series. Both horizontal and vertical distribution of radiated patterns have been systematically presented. To achieve accurate data, the height error caused by Earth curvature has been revised. The $7220 \mathrm{~A}$ antenna array radiates a good steady fan-shaped distribution up to $\pm 40^{\circ}$. There are three altitude of contour plane have been researched. The three height values $\left(\mathrm{h}_{\mathrm{fly}}=300 \mathrm{~m}, 600 \mathrm{~m}, 1200 \mathrm{~m}\right)$ represent the altitude of flight check, below and above it. All of these three contour plane could answer the needs of coverage requirement. The higher one owns larger coverage area but exists a little coverage insufficient near the top of antenna array. Also, in vertical distribution study, there are four representative kind of height of antenna $\left(h_{a}=2.5 \mathrm{~m}, 3.0 \mathrm{~m}, 3.5 \mathrm{~m}\right.$, $4.0 \mathrm{~m}$ ) have been compared. The higher radiated antenna array possesses comparatively larger coverage region, and embodies linear increasing rule. 


\section{Acknowledgements}

Heartfelt acknowledgements would be given to engineer Mingjia $\mathrm{Li}$, who provided the theoretical idea of contour plane for us to establish the free space antenna radiate mathematical model.

\section{References}

[1] Watt Jr., C.B. The Instrument Landing System: Replace it, or Repair it? The Journal of Navigation [J], 2003, 56(03):411-427

[2] Normarc. Normarc 3522 Instruction manual [M], Park Air Systems, 2011

[3] Normarc. Normarc 3523B Instruction manual [M], 21450-39, Park Air Systems, 2011

[4] Normarc. Normarc 3524 Instruction manual [M], 21451-75, Park Air Systems, 2005

[5] Normarc. Normarc 3525 Instruction manual [M], 21452-0610, Park Air Systems, 2011

[6] Normarc. Normarc 3526 Instruction manual [M], 21453-32, Park Air Systems, 2011

[7] Normarc. Normarc 7212A Instruction manual [M], 23746-018, Park Air Systems, 2012

[8] Normarc. Normarc 7212C Instruction manual [M], 70375-012, Park Air Systems, 2012

[9] Normarc. Normarc 7216A Instruction manual [M], 24797-013, Park Air Systems, 2012

[10] Normarc. Normarc 7216C Instruction manual [M], 71507-01, Park Air Systems, 2012

[11] Normarc. Normarc 7220A Instruction manual [M], 24136-015, Park Air Systems, 2012

[12] Normarc. Normarc 7220B Instruction manual [M], 24137-015, Park Air Systems, 2012

[13] Thales. Thales ILS-LOC 411-Technical Manual [M], Thales Antenna Systems, 2000, 1(B),

[14] C.Q.Qu. Research on signal of field monitor of 7220A localizer beacon subsystem of ILS [J]. Open Journal of Antennas and Propagation, 2015, 3(4):37-50.

[15] Annex 10, Aeronautical Telecommunications, vol. I, 3.1.3.3.1, [S], International Civil Aviation Organization 2006 